\title{
Surgical Treatment of Moderate Ischemic Mitral Regurgitation
}

\author{
P.K. Smith, J.D. Puskas, D.D. Ascheim, P. Voisine, A.C. Gelijns, A.J. Moskowitz, \\ J.W. Hung, M.K. Parides, G. Ailawadi, L.P. Perrault, M.A. Acker, M. Argenziano, \\ V. Thourani, J.S. Gammie, M.A. Miller, P. Pagé, J.R. Overbey, E. Bagiella, F. Dagenais, \\ E.H. Blackstone, I.L. Kron, D.J., E.A. Rose, E.G. Moquete, N. Jeffries, T.J. Gardner, \\ P.T. O'Gara, J.H. Alexander, and R.E. Michler, for the Cardiothoracic Surgical \\ Trials Network Investigators*
}

The authors' full names, academic degrees, and affiliations are listed in the Appendix. Address reprint requests to $\mathrm{Dr}$. Gelijns at the Department of Population Health Science and Policy, Icahn School of Medicine at Mount Sinai, 1 Gustave L. Levy PI., Box 1077, New York, NY 10029, or at annetine.gelijns@mssm.edu.

*The Cardiothoracic Surgical Trials Network investigators are listed in the Supplementary Appendix, available at NEJM.org.

This article was published on November 18 , 2014, and updated on December 4, 2014, at NEJM.org.

N Eng|J Med 2014;371:2178-88. DOI: 10.1056/NEJMoa1410490

Copyright (๑) 2014 Massachusetts Medical Society.

\section{A BSTRACT}

\section{BACKGROUND}

Ischemic mitral regurgitation is associated with increased mortality and morbidity. For surgical patients with moderate regurgitation, the benefits of adding mitralvalve repair to coronary-artery bypass grafting (CABG) are uncertain.

METHODS

We randomly assigned 301 patients with moderate ischemic mitral regurgitation to CABG alone or CABG plus mitral-valve repair (combined procedure). The primary end point was the left ventricular end-systolic volume index (LVESVI), a measure of left ventricular remodeling, at 1 year. This end point was assessed with the use of a Wilcoxon rank-sum test in which deaths were categorized as the lowest LVESVI rank. RESULTS

At 1 year, the mean LVESVI among surviving patients was $46.1 \pm 22.4 \mathrm{ml}$ per square meter of body-surface area in the CABG-alone group and $49.6 \pm 31.5 \mathrm{ml}$ per square meter in the combined-procedure group (mean change from baseline, -9.4 and $-9.3 \mathrm{ml}$ per square meter, respectively). The rate of death was $6.7 \%$ in the combined-procedure group and $7.3 \%$ in the CABG-alone group (hazard ratio with mitral-valve repair, 0.90; $95 \%$ confidence interval, 0.38 to $2.12 ; \mathrm{P}=0.81$ ). The rank-based assessment of LVESVI at 1 year (incorporating deaths) showed no significant between-group difference ( $z$ score, $0.50 ; \mathrm{P}=0.61$ ). The addition of mitral-valve repair was associated with a longer bypass time $(\mathrm{P}<0.001)$, a longer hospital stay after surgery $(\mathrm{P}=0.002)$, and more neurologic events $(\mathrm{P}=0.03)$. Moderate or severe mitral regurgitation was less common in the combined-procedure group than in the CABG-alone group (11.2\% vs. $31.0 \%, \mathrm{P}<0.001)$. There were no significant between-group differences in major adverse cardiac or cerebrovascular events, deaths, readmissions, functional status, or quality of life at 1 year.

CONCLUSIONS

In patients with moderate ischemic mitral regurgitation, the addition of mitral-valve repair to CABG did not result in a higher degree of left ventricular reverse remodeling. Mitral-valve repair was associated with a reduced prevalence of moderate or severe mitral regurgitation but an increased number of untoward events. Thus, at 1 year, this trial did not show a clinically meaningful advantage of adding mitral-valve repair to CABG. Longer-term follow-up may determine whether the lower prevalence of mitral regurgitation translates into a net clinical benefit. (Funded by the National Institutes of Health and the Canadian Institutes of Health Research; ClinicalTrials.gov number, NCT00806988.) 
ACH YEAR, APPROXIMATELY 1 MILLION Americans have a myocardial infarction, and nearly 8 million Americans have a history of myocardial infarction. ${ }^{1}$ Ischemic mitral regurgitation, which results from functional-valve incompetence due to myocardial injury and adverse left ventricular remodeling, develops in approximately $50 \%$ of patients after an infarction, and moderate regurgitation occurs in more than $10 \%$ of patients. ${ }^{2-4}$ Ischemic mitral regurgitation is associated with excess mortality regardless of management. ${ }^{5,6}$ The valve leaflets and chordal structures in affected patients are "innocent bystanders"; mitral regurgitation results from papillary muscle displacement, leaflet tethering, reduced closing forces, and annular dilatation..$^{7-10}$ Many patients with ischemic mitral regurgitation require surgical revascularization for multivessel coronary artery disease, at which time surgeons often consider concomitant mitral-valve repair.

Although ischemic mitral regurgitation in patients undergoing coronary-artery bypass grafting (CABG) is associated with adverse outcomes, ${ }^{4,11-14}$ the benefits of adding mitral-valve repair are uncertain. Proponents of CABG alone for the treatment of moderate ischemic mitral regurgitation argue that revascularization may improve regional left ventricular function and reduce the left ventricular chamber size, thereby restoring the functional integrity of the subchordal mitralvalve apparatus. ${ }^{15-17}$ Advocates for mitral-valve repair in addition to $\mathrm{CABG}$ cite the adverse consequences of persistent ischemic mitral regurgitation and further argue that in patients with reduced left ventricular function, mitral-valve repair may prevent progressive adverse remodeling, improve cardiac function, and reduce the risk of heart failure. ${ }^{18,19}$

Operative mortality associated with either procedure has declined steadily during the past 5 years, but the open heart exposure and longer durations of aortic cross-clamping and cardiopulmonary bypass that are associated with mitral-valve repair increase perioperative risk. ${ }^{20,21}$ Thus, the addition of mitral-valve repair to CABG remains controversial. This controversy is based in part on the lack of data from rigorous trials that could help determine whether the potential benefits of mitral-valve repair outweigh the increased risks of the combined procedure.

\section{METHODS}

TRIAL DESIGN AND OVERSIGHT

The design of this trial, which was conducted at 26 centers in the Cardiothoracic Surgical Trials Network, has been published previously. ${ }^{22}$ A coordinating center, an independent adjudication committee, and a data and safety monitoring board that was appointed by the National Institutes of Health oversaw trial progress. The institutional review board at each participating center approved the protocol, which is available with the full text of this article at NEJM.org. All the authors vouch for the fidelity of this report to the protocol. All the patients provided written informed consent.

\section{PATIENTS AND INTERVENTIONS}

Adults with multivessel coronary artery disease and moderate ischemic mitral regurgitation were eligible for enrollment in the study. The severity of ischemic mitral regurgitation was assessed by means of transthoracic echocardiography performed by local echocardiographers using integrative criteria and was confirmed by an independent core laboratory. Moderate ischemic mitral regurgitation was defined by the presence of at least two of three criteria recommended by the American Society of Echocardiography: an effective regurgitant orifice area of 0.2 to less than $0.4 \mathrm{~cm}^{2}$, a vena contracta width of 3 to less than $7 \mathrm{~mm}$, and a ratio of the mitral regurgitant jet area to the left atrial area of $20 \%$ to less than $40 \% .^{23}$ Supportive criteria included the chamber size, the eccentricity of the jet, the E-wave height, and the pulmonary-vein Doppler flow pattern. Qualifying transthoracic echocardiography was performed before surgery. Detailed eligibility criteria have been reported previously. ${ }^{22}$

Intraoperative transesophageal echocardiography was performed to confirm the absence of a mitral-valve structural abnormality and the ability to establish cardiopulmonary bypass safely. Patients were then randomly assigned to undergo CABG alone or CABG plus mitral-valve repair (combined procedure). Randomization was stratified according to center and performed in blocks, with a 1:1 ratio of treatment assignments.

The protocol mandated the use of a rigid or semirigid complete annuloplasty ring in patients 
undergoing mitral-valve repair, unless the ring was contraindicated intraoperatively. Ring sizing was based on the size of the anterior leaflet or on the intercommissural or intertrigonal distance, and the ring was downsized by two sizes when possible to correct for annular dilatation. The specific ring type, implantation technique, and myocardialpreservation method were at the surgeon's discretion. CABG was performed with the use of standard techniques and was supported by cardiopulmonary bypass. All patients were to receive guideline-directed medical therapy by their treating physicians.

\section{END POINTS}

Patients were evaluated for end points at 6 and 12 months; 24-month follow-up is ongoing. Investigators were unaware of end-point data. The primary end point of the trial was the degree of left ventricular reverse remodeling at 12 months, as measured by means of the left ventricular endsystolic volume index (LVESVI) on the basis of transthoracic echocardiography. Site echocardiographers were trained extensively in left ventricular measurement, including the use of contrast agents for endocardial-border delineation, when necessary. Secondary end points included a composite of major adverse cardiac or cerebrovascular events (death, stroke, subsequent mitralvalve surgery, hospitalization for heart failure, or an increase of one or more classes in the New York Heart Association [NYHA] classification), mortality, serious adverse events, degree of residual mitral regurgitation, functional status (according to the NYHA and Canadian Cardiovascular Society classifications), quality of life (as assessed by means of the Minnesota Living with Heart Failure questionnaire and the physical and mental subscales of the Medical Outcomes Study 12-Item Short Form Health Survey [SF-12], and the EuroQoL Group 5-Dimension Self-Report Questionnaire), and rehospitalization.

\section{STATISTICAL ANALYSIS}

We assumed a baseline mean LVESVI of $80 \mathrm{ml}$ per square meter of body-surface area, a standard deviation of $35 \mathrm{ml}$ per square meter for baseline and 1-year LVESVI in both treatment groups, and improvements of $4 \mathrm{ml}$ per square meter in the CABG-alone group and $16 \mathrm{ml}$ per square meter in the combined-procedure group. ${ }^{9,19}$ Given these assumptions, we calculated that enrollment of 300 patients would provide $90 \%$ power to detect a difference of $12 \mathrm{ml}$ per square meter in the LVESVI between groups. We planned one interim analysis using a group-sequential monitoring procedure with a Lan-DeMets stopping boundary and O'Brien-Fleming spending function. ${ }^{24,25}$ The primary null hypothesis was that there would be no significant between-group difference in the LVESVI at 12 months. We tested this hypothesis in an intention-to-treat analysis using a two-tailed Wilcoxon rank-sum test, at a 0.05 alpha level. This analysis accommodated missing LVESVI outcomes owing to death by assigning deceased patients the worst ranks in order according to the time of death. In the case of data that were missing for reasons other than death, we used multiple imputation to calculate the 12-month LVESVI on the assumption that the data were missing at random. We used the HodgesLehmann estimator to quantify between-group differences in the reduction of the LVESVI from baseline. Sensitivity analyses for the LVESVI assessed the robustness of findings with respect to protocol deviations, missing data, and deaths.

Rates of major adverse cardiac or cerebrovascular events and death from any cause were compared between groups with the use of the log-rank test; hazard ratios from Cox regression models were used to quantify relative risks. Between-group differences in rates of adverse events were tested with the use of Poisson regression, differences in functional status were assessed with the use of chi-square tests, and differences in quality-of-life scores were assessed with the use of t-tests.

\section{RESULTS}

\section{PATIENTS}

Between 2009 and 2013, a total of 725 patients were deemed to be eligible for the study, and 301 underwent randomization (151 to CABG alone and 150 to CABG plus mitral-valve repair) (Fig. S1 in the Supplementary Appendix, available at NEJM.org). The two groups had similar baseline characteristics, with the exception of atrial fibrillation, which was more common in the CABGalone group (Table 1$)$. The mean $( \pm S D)$ LVESVI was $54.8 \pm 24.9 \mathrm{ml}$ per square meter in the CABGalone group and $59.6 \pm 25.7 \mathrm{ml}$ per square meter 


\begin{tabular}{|c|c|c|}
\hline Characteristic & $\begin{array}{l}\text { CABG Alone } \\
(\mathrm{N}=151)\end{array}$ & $\begin{array}{c}\text { CABG plus } \\
\text { Mitral-Valve Repair } \\
(N=150)\end{array}$ \\
\hline Male sex — no. (\%) & $99(65.6)$ & $106(70.7)$ \\
\hline Age $-y r$ & $65.2 \pm 11.3$ & $64.3 \pm 9.6$ \\
\hline White race - no. $(\%) \dagger$ & $122(80.8)$ & $115(76.7)$ \\
\hline Hispanic ethnic group — no. (\%)† & $14(9.3)$ & $12(8.0)$ \\
\hline \multicolumn{3}{|l|}{ Medical and surgical history — no./total no. (\%) } \\
\hline Diabetes & $66 / 151(43.7)$ & $76 / 150(50.7)$ \\
\hline Renal insufficiency & $28 / 150(18.7)$ & $24 / 150(16.0)$ \\
\hline Previous CABG & $4 / 143(2.8)$ & $4 / 144(2.8)$ \\
\hline Previous $\mathrm{PCl}$ & 24/151 (15.9) & $26 / 150(17.3)$ \\
\hline Heart failure & $76 / 151(50.3)$ & $82 / 150(54.7)$ \\
\hline Myocardial infarction & $97 / 151(64.2)$ & $103 / 150(68.7)$ \\
\hline Atrial fibrillation & $35 / 150(23.3)$ & $19 / 149(12.8)$ \\
\hline Implantable cardioverter-defibrillator & $6 / 151(4.0)$ & $6 / 150(4.0)$ \\
\hline Stroke & $9 / 151(6.0)$ & $15 / 150(10.0)$ \\
\hline Left ventricular end-systolic volume index $-\mathrm{ml} / \mathrm{m}^{2}$ & $54.8 \pm 24.9$ & $59.6 \pm 25.7$ \\
\hline Left ventricular ejection fraction - \% & $41.2 \pm 11.6$ & $39.3 \pm 10.9$ \\
\hline Effective regurgitant orifice area $-\mathrm{cm}^{2}$ & $0.2 \pm 0.1$ & $0.2 \pm 0.1$ \\
\hline \multicolumn{3}{|l|}{ Grade on CCS angina scale - no./total no. (\%) } \\
\hline No angina & $45 / 150(30.0)$ & $50 / 149(33.6)$ \\
\hline Class III or IV & $51 / 150(34.0)$ & $46 / 149(30.9)$ \\
\hline NYHA class III or IV - no. (\%)』 & $67(44.4)$ & $55(36.7)$ \\
\hline Minnesota Living with Heart Failure score & $43.0 \pm 27.2$ & $40.4 \pm 27.5$ \\
\hline \multicolumn{3}{|l|}{ Concomitant procedure - no. (\%) } \\
\hline Management of left atrial appendage $\|$ & $8(5.3)$ & $12(8.0)$ \\
\hline Atrial maze procedure & $10(6.6)$ & $11(7.3)$ \\
\hline No. of grafts & $3.3 \pm 0.9$ & $3.2 \pm 0.9$ \\
\hline Duration of aortic cross-clamping - min & $74.7 \pm 36.7$ & $117.2 \pm 35.4$ \\
\hline Duration of cardiopulmonary bypass - min & $106.8 \pm 49.7$ & $163.1 \pm 54.9$ \\
\hline
\end{tabular}

* Plus-minus values are means \pm SD. There were no significant differences in baseline and operative characteristics between the study groups except for atrial fibrillation $(P=0.02)$, duration of aortic cross-clamping $(P<0.001)$, and duration of cardiopulmonary bypass $(\mathrm{P}<0.001)$. CABG denotes coronary-artery bypass grafting, and $\mathrm{PCl}$ percutaneous coronary intervention.

$\uparrow$ Race and ethnic group were self-reported.

In the Canadian Cardiovascular Society (CCS) classification of angina, grade III indicates marked limitation of ordinary physical activity, with an ability to walk one or two blocks on the level and to climb one flight of stairs in normal conditions and at a normal pace; grade IV indicates an inability to carry on any physical activity without discomfort, with angina at rest in some cases.

$\int$ New York Heart Association (NYHA) classes range from I to IV, with higher classes indicating worse condition.

9 Scores on the Minnesota Living with Heart Failure questionnaire range from 0 to 105, with higher scores indicating worse condition.

|| These procedures involved closure or ligation of the left atrial appendage.

in the combined-procedure group. The echocardiography core laboratory confirmed the diagnosis of moderate mitral regurgitation in $93 \%$ of the patients ( $4 \%$ of the patients had severe regurgitation, and $3 \%$ had mild regurgitation). The use of anti-ischemic medications and heart-failure therapies was similar in the two study groups.

Additional concomitant procedures were performed in $19 \%$ of the patients. Investigators used complete annuloplasty rings in all patients 


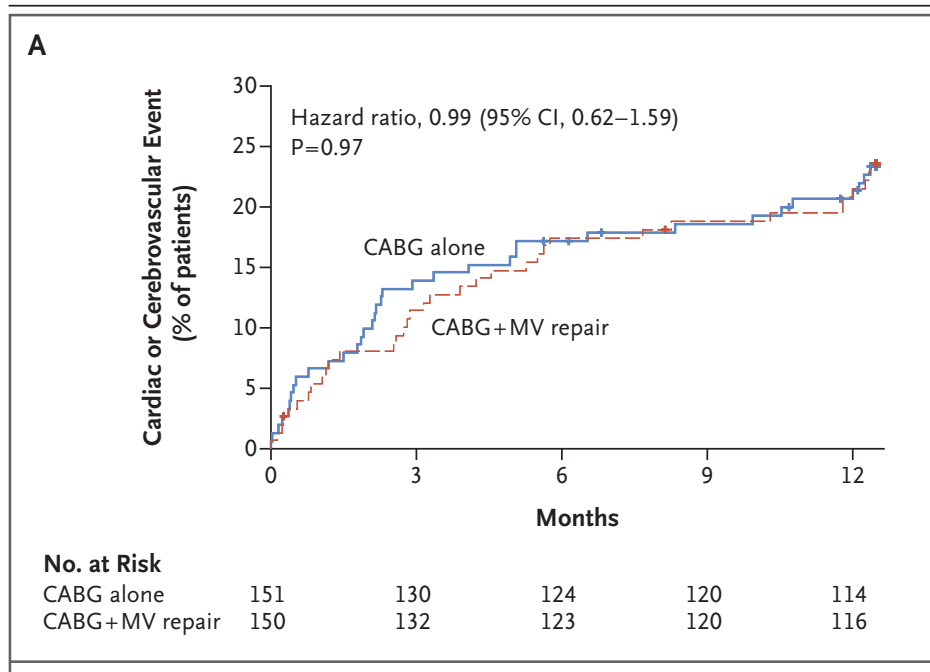

B

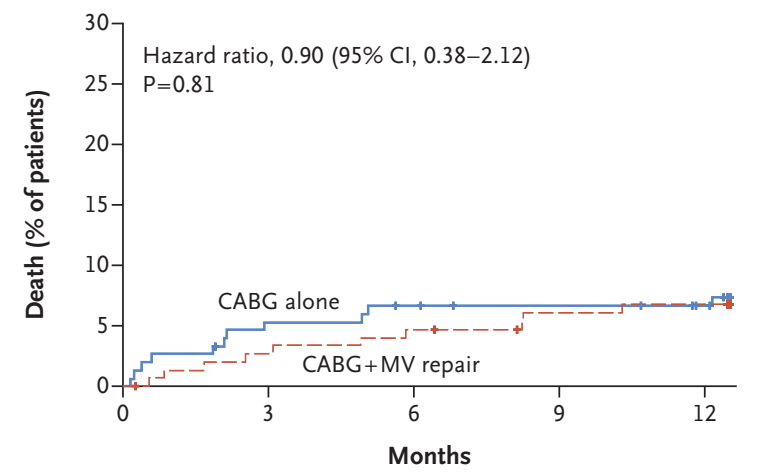

No. at Risk CABG alone CABG $+M V$ repair 1 repair 150

Figure 1. Time-to-Event Curves for the Composite End Point of Cardiac or Cerebrovascular Events and Death, According to Treatment Group.

The composite end point of major adverse cardiac or cerebrovascular events included death, stroke, subsequent mitral-valve (MV) surgery, hospitalization for heart failure, and an increase of one or more classes in the New York Heart Association (NYHA) classification. Crosses indicate censoring of data at the indicated time point. CABG denotes coronary-artery bypass surgery. an increase in the severity of mitral regurgitation on intraoperative transesophageal echocardiography. The most common reason for crossover to CABG alone was the surgeon's concern about the risk associated with valve repair.

\section{LEFT VENTRICULAR DIMENSION AND RESIDUAL MITRAL REGURGITATION}

At 12 months, the mean LVESVI among surviving patients was $46.1 \pm 22.4 \mathrm{ml}$ per square meter in the CABG-alone group and $49.6 \pm 31.5 \mathrm{ml}$ per square meter in the combined-procedure group (mean change from baseline, -9.4 and $-9.3 \mathrm{ml}$ per square meter, respectively). The rate of death was $6.7 \%$ in the combined-procedure group and $7.3 \%$ in the CABG-alone group (hazard ratio with mitralvalve repair, 0.90; 95\% confidence interval [CI], 0.38 to $2.12 ; \mathrm{P}=0.81$ ). The rank-based assessment of LVESVI at 12 months (incorporating deaths) showed no significant difference between treatment groups ( $z$ score, $0.50 ; \mathrm{P}=0.61$ ). The mean left ventricular ejection fraction at 12 months was $45.1 \pm 10.2 \%$ in the CABG-alone group and $43.9 \pm 11.2 \%$ in the combined-procedure group.

The proportion of surviving patients with residual mitral regurgitation (moderate or severe) at 12 months was significantly higher in the CABG-alone group than in the combined-procedure group (31.0\% [moderate, $25.9 \%$; severe, $5.2 \%$ ] vs. $11.2 \%$ [moderate, $10.4 \%$; severe, $0.8 \%$ ]; $\mathrm{P}<0.001$ ). Within 1 year, two patients, both of whom were in the combined-procedure group, underwent mitral-valve reoperation, and none of the patients in the CABG-alone group underwent subsequent mitral-valve surgery ( $\mathrm{P}=0.25$ for the betweengroup comparison).

\section{CARDIAC OR CEREBROVASCULAR EVENTS AND DEATH}

At 12 months, there was no significant betweengroup difference with respect to the composite end point of major adverse cardiac or cerebrovascular events (hazard ratio, 0.99; 95\% CI, 0.62 to 1.59; $\mathrm{P}=0.97$ ) (Fig. $1 \mathrm{~A}$ ) or any of its individual components (Table 2). The 30-day rate of death did not differ significantly between treatment groups (2.7\% in the CABG-alone group and $1.3 \%$ in the combined-procedure group, $\mathrm{P}=0.68$ ). At 12 months, we observed no significant difference in cumulative mortality between treatment groups (Fig. 1B). Overall, the most frequent causes of death were heart failure (accounting for $23.8 \%$ of deaths), sepsis (14.3\%), and respiratory failure (9.5\%). 


\begin{tabular}{|c|c|c|c|}
\hline \multirow[t]{2}{*}{ End Point or Event } & $\begin{array}{c}\text { CABG Alone } \\
(N=151)\end{array}$ & $\begin{array}{l}\text { CABG plus } \\
\text { Mitral-Valve Repair } \\
(N=150)\end{array}$ & \multirow[t]{2}{*}{ P Value } \\
\hline & \multicolumn{2}{|c|}{ no. of patients (\%) } & \\
\hline \multicolumn{4}{|l|}{ Clinical end points } \\
\hline Death & $11(7.3)$ & $10(6.7)$ & 0.83 \\
\hline Stroke & $2(1.3)$ & $6(4.0)$ & 0.17 \\
\hline Increase of one or more classes in NYHA classification & $9(6.0)$ & $12(8.0)$ & 0.49 \\
\hline Rehospitalization for heart failure & $20(13.2)$ & $22(14.7)$ & 0.72 \\
\hline Mitral-valve reoperation & 0 & $2(1.3)$ & 0.25 \\
\hline \multirow[t]{2}{*}{ Composite end point* } & $38(25.2)$ & $38(25.3)$ & 0.97 \\
\hline & \multicolumn{2}{|c|}{ no. of events (no./100 patient- $y$ r) } & \\
\hline \multicolumn{4}{|l|}{ Serious adverse events } \\
\hline Any & $153(117.0)$ & $185(137.1)$ & 0.15 \\
\hline Heart failure & $30(22.9)$ & $31(23.0)$ & 1.00 \\
\hline \multicolumn{4}{|l|}{ Neurologic event $†$} \\
\hline Any & $4(3.1)$ & $13(9.6)$ & 0.03 \\
\hline Stroke & $2(1.5)$ & $7(5.2)$ & 0.10 \\
\hline \multicolumn{4}{|l|}{ Myocardial infarction } \\
\hline Nonperioperative & $1(0.8)$ & $1(0.7)$ & 0.98 \\
\hline Perioperative & $1(0.8)$ & 0 & 0.32 \\
\hline Renal failure & $4(3.1)$ & $5(3.7)$ & 0.77 \\
\hline Bleeding & $4(3.1)$ & $2(1.5)$ & 0.40 \\
\hline \multicolumn{4}{|l|}{ Arrhythmia } \\
\hline Supraventricular & $11(8.4)$ & $24(17.8)$ & 0.03 \\
\hline Ventricular & $5(3.8)$ & $2(1.5)$ & 0.24 \\
\hline Localized infection & $16(12.2)$ & $16(11.9)$ & 0.93 \\
\hline Sepsis & $6(4.6)$ & $8(5.9)$ & 0.63 \\
\hline Respiratory failure & $8(6.1)$ & $8(5.9)$ & 0.95 \\
\hline \multicolumn{4}{|l|}{ Hospitalization } \\
\hline Any rehospitalization & $90(71.6)$ & $88(68.5)$ & 0.76 \\
\hline Readmission for cardiovascular causes & $53(42.2)$ & $46(35.8)$ & 0.42 \\
\hline
\end{tabular}

* The composite end point of major cardiac or cerebrovascular adverse events included death, stroke, hospitalization for heart failure, worsening heart failure, mitral-valve reintervention, and an increase of one or more classes in the NYHA classification.

$\dagger$ In the group assigned to CABG alone, there were two cases of stroke, one case of transient ischemic attack, and one case of seizure-related disorder. In the group assigned to CABG with mitral-valve repair, there were seven cases of stroke, three cases of toxic metabolic encephalopathy, two cases of seizure-related disorder, and one case of a duralbased mass.

\section{ADVERSE EVENTS AND HOSPITALIZATION}

The number of serious adverse events was similar in the two treatment groups at 1 year (185 events in the combined-procedure group and 153 events in the CABG-alone group, $\mathrm{P}=0.15$ ). However, the rate of serious neurologic adverse events, includ- ing stroke, transient ischemic attack, and metabolic encephalopathy, was significantly higher in the combined-procedure group ( $\mathrm{P}=0.03)$, as was the rate of supraventricular arrhythmias $(\mathrm{P}=0.03)$ (Table 2). The duration of the index hospitalization was similar in the CABG-alone and com- 


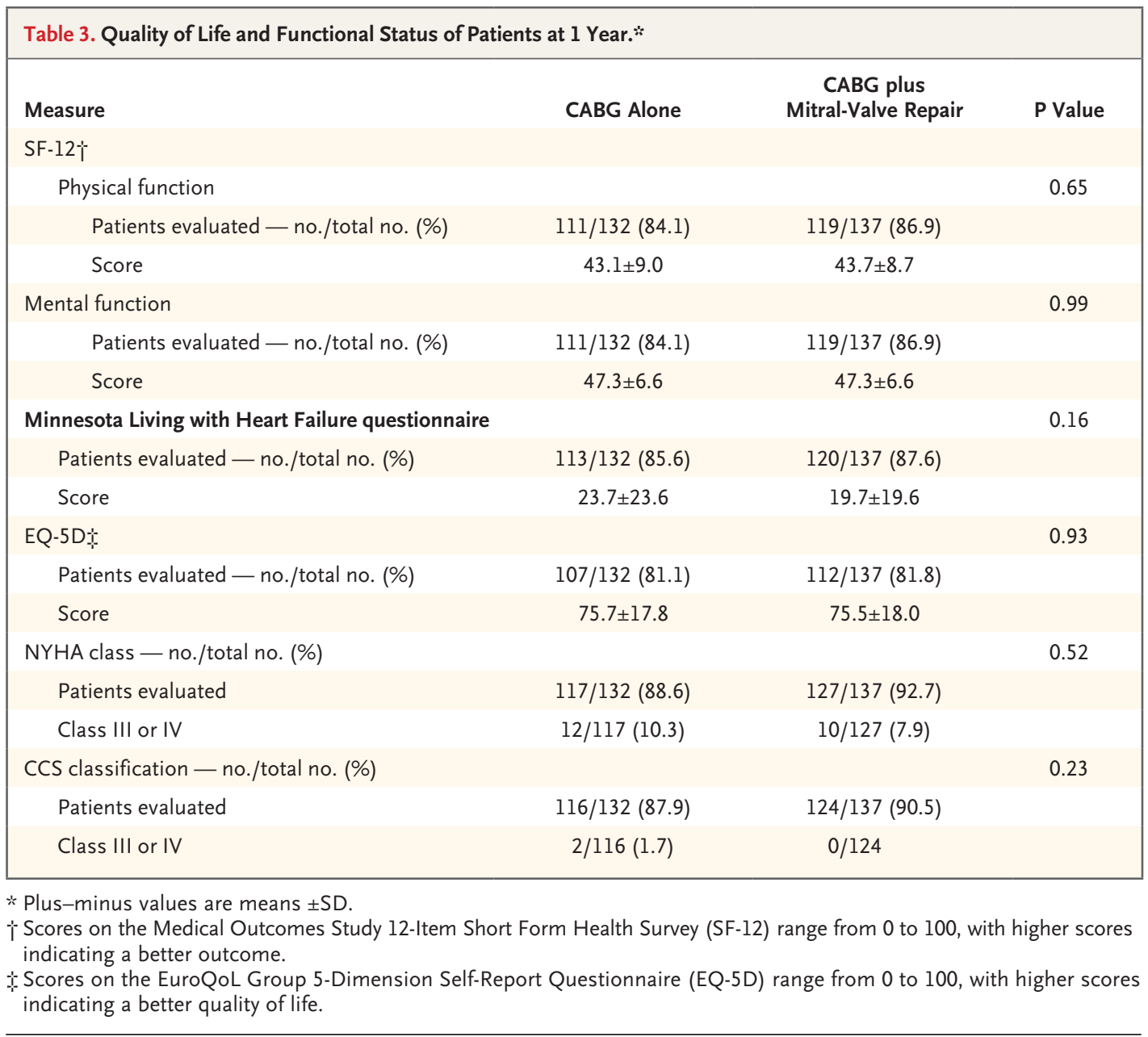

bined-procedure groups (mean, 14.2 \pm 7.7 days and $15.2 \pm 9.5$ days, respectively; $\mathrm{P}=0.47$; and median, 13 days in each group). However, the mean length of stay after surgery was shorter with CABG alone than with the combined procedure $(9.4 \pm 5.9$ days vs. $11.3 \pm 8.2$ days, $\mathrm{P}=0.002$ ), as was the mean length of stay in the intensive care unit (ICU) (4.0 \pm 5.7 days vs. $4.8 \pm 6.1$ days, $P=0.006$ ). There were no significant differences in rates of readmission between the two groups.

\section{QUALITY OF LIFE}

There was no significant difference between treatment groups with respect to any measure of quality of life or functional status among surviving patients at 12 months (Table 3). As measured by the score on the Minnesota Living with Heart Failure questionnaire, there was a median reduction from baseline in heart-failure symptoms of
$44.8 \%$ in the CABG-only group and $48.1 \%$ in the combined-procedure group. Similarly, as measured by the score on the SF-12 physical subscale, there was improvement over baseline in physical health of $12.0 \%$ in the CABG-alone group and $14.3 \%$ in the combined-procedure group. Figure 2 shows the NYHA class and mortality over time.

\section{DISCUSSION}

Moderate ischemic mitral regurgitation is common among patients referred for surgical revascularization, especially after a myocardial infarction. The preferred treatment strategy for these patients has not been established. There are many observational studies supporting the benefits of adding mitral-valve repair to CABG, ${ }^{19,26,27}$ many refuting the benefits,, $528-30$ and several with neutral findings. ${ }^{31,32}$ Moreover, recent guidelines 
state that concomitant mitral-valve repair may be beneficial but that the evidence is inconclusive. ${ }^{33,34}$ This trial evaluated the efficacy and safety of adding mitral-valve repair to CABG for patients with moderate ischemic mitral regurgitation.

Left ventricular remodeling, as measured by means of the LVESVI (the primary end point in our trial), is a predictor of a poor prognosis for patients with ischemic myocardial disease, and therapeutic efforts to reverse adverse remodeling have been associated with improved outcomes..$^{35}$ Significant reductions in the LVESVI were observed in both groups in our trial, although there was no significant between-group difference. Moreover, we found that $69 \%$ of patients in the CABGalone group had no mitral regurgitation or mild regurgitation at 1 year, as compared with $89 \%$ of patients in the combined-procedure group. These findings suggest that there was substantial reversible ischemia in both groups that was alleviated by revascularization. A reduction in the degree of mitral regurgitation with CABG alone has been reported previously. ${ }^{14,28,30,31}$

The addition of mitral-valve repair to CABG resulted in longer durations of cardiopulmonary bypass and aortic cross-clamping and longer stays after surgery and in the ICU. The longer bypass time and more complicated surgery, including the obligatory cardiotomy to perform mitral-valve repair, increase the risk of embolization and may explain the increased rate of serious neurologic events in the combined-procedure group. In addition, patients in the combined-procedure group had more supraventricular arrhythmias, which may be related to the atrial incision required for exposure of the mitral valve. Despite the higher proportion of patients with moderate or severe mitral regurgitation at 1 year in the CABG-alone group, 1-year clinical outcomes, including functional status, quality of life, mortality, need for mitral-valve reoperation, and major adverse cardiac or cerebrovascular events, did not differ significantly between the two groups. Longer-term clinical and echocardiographic follow-up is ongoing.

Our results differ from those of two small, randomized trials involving patients with moderate ischemic mitral regurgitation. Fattouch and colleagues randomly assigned 102 patients to CABG alone or CABG with mitral-valve repair and followed the patients for an average of 32 months. ${ }^{36}$

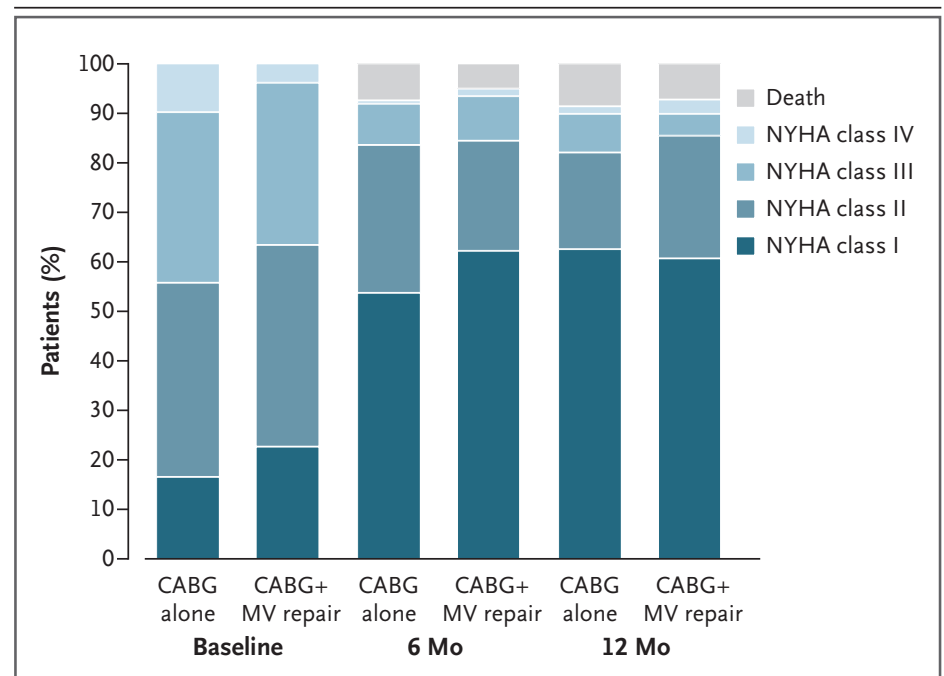

Figure 2. NYHA Class and Death, According to Treatment Group.

The proportions of patients in each NYHA class are shown at baseline and at 6 and 12 months; the proportions of patients who died are shown at 6 and 12 months.

They reported that left ventricular reverse remodeling, the qualitative degree of mitral regurgitation, and NYHA functional class improved with CABG plus mitral-valve repair as compared with CABG alone. The Randomized Ischemic Mitral Evaluation (RIME) trial randomly assigned 73 patients to CABG alone or CABG plus mitralvalve repair. ${ }^{37}$ The trial was terminated early owing to slow enrollment but did show benefits with respect to peak oxygen consumption (the primary end point), regurgitant volume, plasma B-type natriuretic peptide levels, and the LVESVI in patients assigned to CABG with mitral-valve repair as compared with those assigned to CABG alone. The combined-procedure group had a higher rate of balloon-pump use and reoperation for bleeding. In contrast, our study showed similar 1-year outcomes for the two treatment groups with respect to the LVESI, NYHA class, and quality of life. These differences in outcome between our study and the two previous studies may in part reflect differences in end points assessed, methods of classifying mitral regurgitation, the duration of mitral regurgitation from initial diagnosis to trial enrollment, and rates of prior myocardial infarction.

Our trial, like others published to date, was not powered to detect small but important differences in survival. A recent large cohort study involving patients with clinically significant cor- 
onary artery disease and moderate or severe ischemic mitral regurgitation who were treated with a range of methods showed a survival advantage for all forms of revascularization (with or without mitral-valve surgery) as compared with initial medical management, which was associated with a 5 -year survival rate of 52\%. ${ }^{5}$ CABG alone resulted in the largest survival advantage.

Our study participants had lower baseline LVESVI values than we had anticipated, a finding that reflects variation in left ventricular size and severity of mitral regurgitation, as well as inconsistent methods used to assess the severity of mitral regurgitation in previous studies. Although the baseline LVESVI was lower than assumed, so too was its variability, with the statistical power for the study remaining at $90 \%$. Moreover, although we observed larger absolute improvement in patients with a higher baseline LVESVI, the amount of improvement was similar in the two study groups - that is, the baseline LVESVI did not affect the relative benefit of treatment. All the patients enrolled in this trial had ischemic mitral regurgitation; in more than $90 \%$ of patients, the regurgitation was moderate in degree.

This study has several limitations. First, the primary end point was an echocardiographic measure of left ventricular remodeling, not a clinical outcome. A randomized trial with the power to detect a difference in clinical end points would have required thousands of patients and exceeded our capacity for timely enrollment. Our choice of the LVESVI as the primary end point was driven by strong evidence correlating the LVESVI with clinical outcomes, including the NYHA class and rates of hospitalization and survival. ${ }^{38-41} \mathrm{~A}$ risk of using intermediate end points is that they may be inconsistent with clinical end points, raising interpretation issues; however, in our trial, the findings with respect to mortality and the composite end point of cardiac or cerebrovascular events corroborated the LVESVI findings. Second, in everyday practice the surgical decision to repair the mitral valve may be influenced by the results of intraoperative transesophageal echocardiography. In our trial, randomization was based solely on the results of preoperative transthoracic echocardiography, with no adjustment for intravascular volumes and vascular resistance. The reliance on preoperative transthoracic echocardiography may have affected the generalizability of our results. Finally, we report here on a relatively short follow-up period of 12 months. Follow-up will continue for 24 months, during which time differences in the durability of improvement in mitral regurgitation and any associated effects on clinical outcomes might become apparent.

In conclusion, we found that in patients with moderate ischemic mitral regurgitation who were referred for $\mathrm{CABG}$, the addition of mitral-valve repair to CABG, as compared with CABG alone, was not associated with greater improvement in the LVESVI at 1 year after surgery. There were also no significant between-group differences in mortality, the composite end point of cardiac or cerebrovascular events, readmissions, or quality of life. The proportion of patients with residual mitral regurgitation of at least moderate severity was significantly lower with the addition of mitral-valve repair; however, patients undergoing repair had more neurologic events than patients undergoing CABG alone. At 1 year, this trial did not show a clinically meaningful advantage of adding mitralvalve repair to CABG. Longer-term follow-up may determine whether the observed difference in the prevalence of moderate or severe mitral regurgitation at 1 year will translate into a net clinical benefit for patients undergoing repair.

Supported by a cooperative agreement (U01 HL088942) with the National Heart, Lung, and Blood Institute, including funding by the National Institute of Neurological Disorders and Stroke and the Canadian Institutes of Health Research.

Dr. Acker reports receiving consulting fees from Thoratec and HeartWare. Dr. Gelijns reports holding equity in MERS International. Dr. Thourani reports receiving grant support from Edwards Lifesciences, St. Jude Medical, and Sorin Medical. No other potential conflict of interest relevant to this article was reported.

Disclosure forms provided by the authors are available with the full text of this article at NEJM.org.

APPENDIX

The authors' full names and academic degrees are as follows: Peter K. Smith, M.D., John D. Puskas, M.D., Deborah D. Ascheim, M.D., Pierre Voisine, M.D., Annetine C. Gelijns, Ph.D., Alan J. Moskowitz, M.D., Judy W. Hung, M.D., Michael K. Parides, Ph.D., Gorav Ailawadi, M.D., Louis P. Perrault, M.D., Michael A. Acker, M.D., Michael Argenziano, M.D., Vinod Thourani, M.D., James S. Gammie, M.D., Marissa A. Miller, D.V.M., Pierre Pagé, M.D., Jessica R. Overbey, M.S., Emilia Bagiella, Ph.D., François Dagenais, M.D., Eugene H. Blackstone, M.D., Irving L. Kron, M.D., Daniel J. Goldstein, M.D., Eric A. Rose, M.D., Ellen G. Moquete, R.N., Neal Jeffries, Ph.D., Timothy J. Gardner, M.D., Patrick T. O’Gara, M.D., John H. Alexander, M.D., and Robert E. Michler, M.D.

The authors' affiliations are as follows: the Division of Cardiovascular and Thoracic Surgery, Department of Surgery (P.K.S.), and Division of Cardiology, Department of Medicine (J.H.A.), Duke University Medical Center, Durham, NC; Department of Cardiac Surgery, Mount 
Sinai Health System (J.D.P., E.A.R.), International Center for Health Outcomes and Innovation Research, Department of Population Health Science and Policy, Icahn School of Medicine at Mount Sinai (D.D.A., A.C.G., A.J.M., M.K.P., J.R.O., E.B., E.G.M.), Division of Cardiothoracic Surgery, Department of Surgery, College of Physicians and Surgeons, Columbia University (M.A.), and Department of Cardiothoracic and Vascular Surgery, Montefiore Medical Center-Albert Einstein College of Medicine (D.J.G., R.E.M.) — all in New York; Institut Universitaire de Cardiologie et de Pneumologie de Québec, Hôpital Laval, Quebec, QC (P.V., F.D.), and Montreal Heart Institute, University of Montreal (L.P.P.), and Department of Surgery, Hôpital du Sacré-Cœur de Montréal (P.P.), Montreal — all in Canada; Echocardiography Core Lab, Massachusetts General Hospital (J.W.H.), and the Cardiovascular Division, Brigham and Women's Hospital (P.T.O.) - both in Boston; Division of Thoracic and Cardiovascular Surgery, University of Virginia School of Medicine, Charlottesville (G.A., I.L.K.); Department of Surgery, Division of Cardiovascular Surgery, University of Pennsylvania School of Medicine, Philadelphia (M.A.A.); Clinical Research Unit, Division of Cardiothoracic Surgery, Emory University School of Medicine, Atlanta (V.T.); University of Maryland, Baltimore (J.S.G.), and the Division of Cardiovascular Sciences (M.A.M.) and Office of Biostatistics Research (N.J.), National Heart, Lung, and Blood Institute, Bethesda - both in Maryland; Department of Thoracic and Cardiovascular Surgery, Cleveland Clinic Foundation, Cleveland (E.H.B.); and the Center for Heart and Vascular Health, Christiana Care Health System, Newark, DE (T.J.G.).

\section{REFERENCES}

1. Go AS, Mozaffarian D, Roger VL, et al. Heart disease and stroke statistics 2014 update: a report from the American Heart Association. Circulation 2014 129(3):e28-e292

2. Bursi F, Enriquez-Sarano $M$, Nkomo VT, et al. Heart failure and death after myocardial infarction in the community: the emerging role of mitral regurgitation. Circulation 2005;111:295-301.

3. Pérez de Isla L, Zamorano J, Quezada $M$, et al. Functional mitral regurgitation after a first non-ST-segment elevation acute coronary syndrome: contribution to congestive heart failure. Eur Heart 2007;28:2866-72.

4. Lamas GA, Mitchell GF, Flaker GC, et al. Clinical significance of mitral regurgitation after acute myocardial infarction. Circulation 1997;96:827-33.

5. Castleberry AW, Williams JB, Danesh mand MA, et al. Surgical revascularization is associated with maximal surviva in patients with ischemic mitral regurgitation: a 20-year experience. Circulation 2014;129:2547-56.

6. Grigioni F, Detaint D, Avierinos JF, Scott C, Tajik J, Enriquez-Sarano M. Contribution of ischemic mitral regurgitation to congestive heart failure after myocardial infarction. J Am Coll Cardiol 2005; 45:260-7.

7. Izumi S, Miyatake K, Beppu S, et al Mechanism of mitral regurgitation in patients with myocardial infarction: a study using real-time two-dimensional Doppler flow imaging and echocardiography. Circulation 1987;76:777-85.

8. Kono $\mathrm{T}$, Sabbah $\mathrm{HN}$, Rosman $\mathrm{H}$ Alam M, Jafri S, Goldstein S. Left ventricular shape is the primary determinant of functional mitral regurgitation in heart failure. J Am Coll Cardiol 1992; 20:1594-8.

9. Yiu SF, Enriquez-Sarano M, Tribouilloy C, Seward JB, Tajik AJ. Determinants of the degree of functional mitral regurgitation in patients with systolic left ventricular dysfunction: a quantitative clinical study. Circulation 2000;102:1400-6. 10. Kumanohoso T, Otsuji Y, Yoshifuku S, et al. Mechanism of higher incidence of ischemic mitral regurgitation in patients with inferior myocardial infarction: quantitative analysis of left ventricula and mitral valve geometry in 103 patients with prior myocardial infarction. J Thorac Cardiovasc Surg 2003;125:135-43.

11. Lam BK, Gillinov AM, Blackstone EH, et al. Importance of moderate ischemic mitral regurgitation. Ann Thorac Surg 2005;79:462-70

12. Schroder JN, Williams ML, Hata JA, et al. Impact of mitral valve regurgitation evaluated by intraoperative transesophageal echocardiography on long-term outcomes after coronary artery bypass grafting. Circulation 2005;112:Suppl:I-293-I-298.

13. Fattouch K, Sampognaro R, Speziale $\mathrm{G}$, et al. Impact of moderate ischemic mitral regurgitation after isolated coronary artery bypass grafting. Ann Thorac Surg 2010;90:1187-94.

14. Mallidi HR, Pelletier MP, Lamb J, et al. Late outcomes in patients with uncorrected mild to moderate mitral regurgitation at the time of isolated coronary artery bypass grafting. J Thorac Cardiovasc Surg 2004;127:636-44.

15. Christenson JT, Simonet F, Bloch A, Maurice J, Velebit V, Schmuziger M. Should a mild to moderate ischemic mitral valve regurgitation in patients with poor left ventricular function be repaired or not? J Heart Valve Dis 1995;4:484-8.

16. Penicka M, Linkova $\mathrm{H}$, Lang $\mathrm{O}$, et al. Predictors of improvement of unrepaired moderate ischemic mitral regurgitation in patients undergoing elective isolated coronary artery bypass graft surgery. Circulation 2009;120:1474-81.

17. Roshanali F, Mandegar MH, Yousefnia MA, Alaeddini F, Wann S. Low-dose dobutamine stress echocardiography to predict reversibility of mitral regurgitation with CABG. Echocardiography 2006; 23:31-7.

18. Flynn M, Curtin R, Nowicki ER, et al. Regional wall motion abnormalities and scarring in severe functional ischemic mitral regurgitation: a pilot cardiovascular magnetic resonance imaging study. J Thorac Cardiovasc Surg 2009;137:1063-70. 19. Bax JJ, Braun J, Somer ST, et al. Restrictive annuloplasty and coronary revascularization in ischemic mitral regurgitation results in reverse left ventricular remodeling. Circulation 2004;110:Suppl: II-103-II-108.

20. ElBardissi AW, Aranki SF, Sheng S, 31. Wong DR, Agnihotri AK, Hung JW, et
O'Brien SM, Greenberg CC, Gammie JS. Trends in isolated coronary artery bypass grafting: an analysis of the Society of Thoracic Surgeons adult cardiac surgery database. J Thorac Cardiovasc Surg 2012; 143:273-81.

21. Lee R, Li S, Rankin JS, et al. Fifteenyear outcome trends for valve surgery in North America. Ann Thorac Surg 2011; 91:677-84.

22. Smith PK, Michler RE, Woo YJ, et al. Design, rationale, and initiation of the Surgical Interventions for Moderate Ischemic Mitral Regurgitation Trial: a report from the Cardiothoracic Surgical Trials Network. J Thorac Cardiovasc Surg 2012;143:111-7.

23. Zoghbi WA, Enriquez-Sarano M, Foster E, et al. Recommendations for evaluation of the severity of native valvular regurgitation with two-dimensional and Doppler echocardiography. J Am Soc Echocardiogr 2003;16:777-802.

24. O'Brien PC, Fleming TR. A multiple testing procedure for clinical trials. Biometrics 1979;35:549-56.

25. Lan KKG, DeMets DL. Discrete sequential boundaries for clinical trials. Biometrika 1983;70:659-63.

26. Aklog L, Filsoufi F, Flores KQ, et al. Does coronary artery bypass grafting alone correct moderate ischemic mitral regurgitation? Circulation 2001;104 Suppl 1:I-68-I-75.

27. Deja MA, Grayburn PA, Sun B, et al. Influence of mitral regurgitation repair on survival in the surgical treatment for ischemic heart failure trial. Circulation 2012;125:2639-48.

28. Kang DH, Kim MJ, Kang SJ, et al. Mitral valve repair versus revascularization alone in the treatment of ischemic mitral regurgitation. Circulation 2006;114: Suppl:I-499-I-503. JS, et al. Survival prognosis and surgical management of ischemic mitral regurgitation. Ann Thorac Surg 2008;86:735-44. 30. Rydén T, Bech-Hanssen O, Brandrupsson A. The importance of grade 2 ischemic mitral regurgitation in coronary artery bypass grafting. Eur J Cardiothorac Surg 2001;20:276-81.
29. Milano CA, Daneshmand MA, Rankin Wognsen G, Nilsson F, Svensson S, Jepp- 
al. Long-term survival after surgical revascularization for moderate ischemic mitral regurgitation. Ann Thorac Surg 2005;80:570-7.

32. Kim YH, Czer LS, Soukiasian HJ, et al. Ischemic mitral regurgitation: revascularization alone versus revascularization and mitral valve repair. Ann Thorac Surg 2005;79:1895-901.

33. Hillis LD, Smith PK, Anderson JL, et al. 2011 ACCF/AHA guideline for coronary artery bypass graft surgery: a report of the American College of Cardiology Foundation/American Heart Association Task Force on Practice Guidelines: developed in collaboration with the American Association for Thoracic Surgery, Society of Cardiovascular Anesthesiologists, and Society of Thoracic Surgeons. J Am Coll Cardiol 2011;58(24):e123-e210.

34. Nishimura RA, Otto CM, Bonow RO, et al. 2014 AHA/ACC guideline for the man- agement of patients with valvular heart disease: a report of the American College of Cardiology/American Heart Association Task Force on Practice Guidelines. J Am Coll Cardiol 2014;63(22):e57-e185. [Erratum, J Am Coll Cardiol 2014;63:2489.]

35. Michler RE, Rouleau JL, Al-Khalidi $\mathrm{HR}$, et al. Insights from the STICH trial: change in left ventricular size after coronary artery bypass grafting with and without surgical ventricular reconstruction. J Thorac Cardiovasc Surg 2013;146:1139-45. 36. Fattouch K, Guccione F, Sampognaro $\mathrm{R}$, et al. Efficacy of adding mitral valve restrictive annuloplasty to coronary artery bypass grafting in patients with moderate ischemic mitral valve regurgitation: a randomized trial. J Thorac Cardiovasc Surg 2009;138:278-85.

37. Chan KM, Punjabi PP, Flather M, et al Coronary artery bypass surgery with or without mitral valve annuloplasty in mod- erate functional ischemic mitral regurgitation: final results of the Randomized Ischemic Mitral Evaluation (RIME) trial. Circulation 2012;126:2502-10.

38. White HD, Norris RM, Brown MA, Brandt PW, Whitlock RM, Wild CJ. Left ventricular end-systolic volume as the major determinant of survival after recovery from myocardial infarction. Circulation 1987;76:44-51.

39. Konstam MA, Udelson JE, Anand IS, Cohn JN. Ventricular remodeling in heart failure: a credible surrogate endpoint. J Card Fail 2003;9:350-3.

40. Carson P, Tognoni G, Cohn JN. Effect of valsartan on hospitalization: results from Val-HeFT. J Card Fail 2003;9:164-71. 41. Moss AJ, Hall WJ, Cannom DS, et al. Cardiac-resynchronization therapy for the prevention of heart-failure events. $\mathrm{N}$ Engl J Med 2009;361:1329-38.

Copyright (๑) 2014 Massachusetts Medical Society.

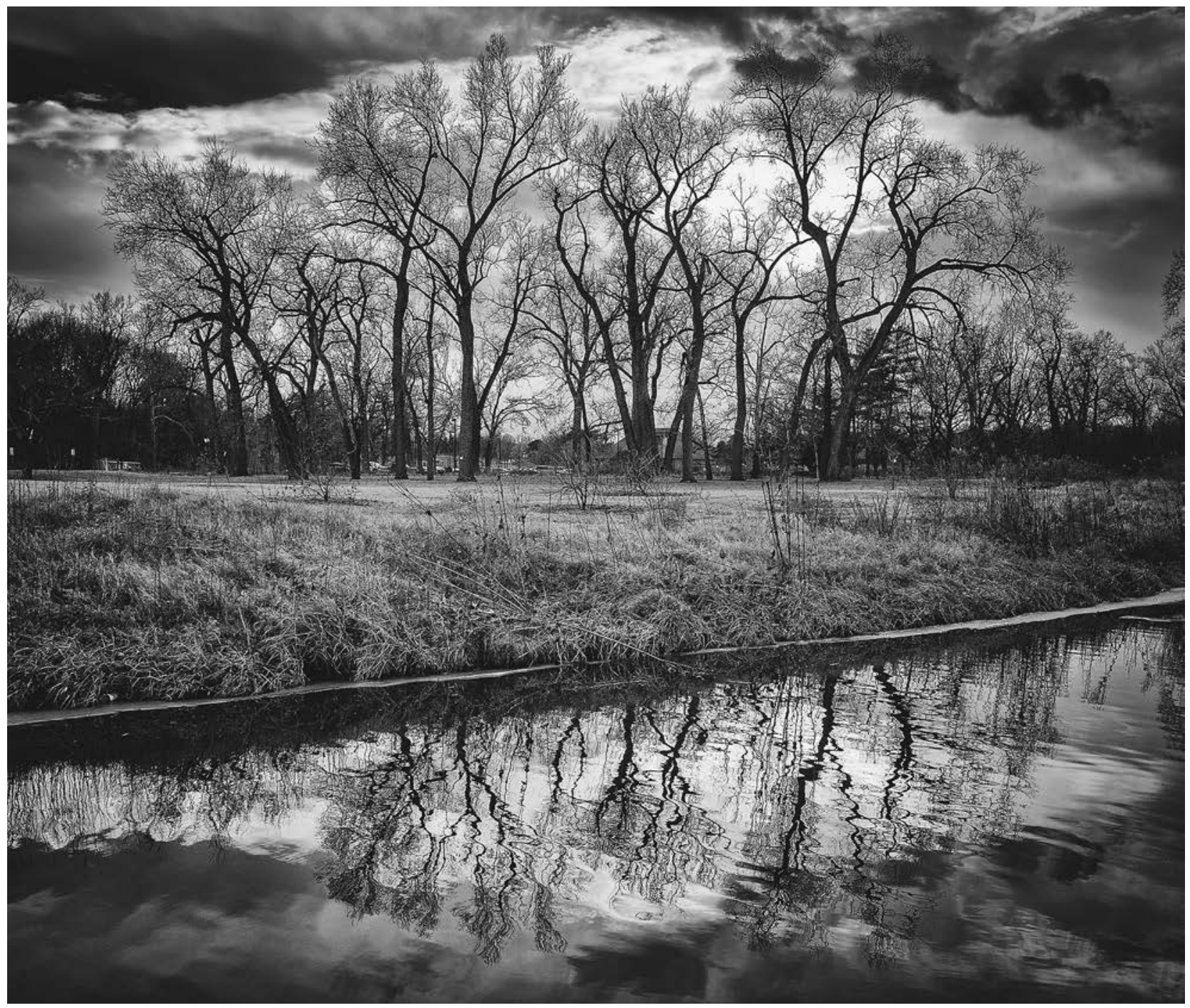

